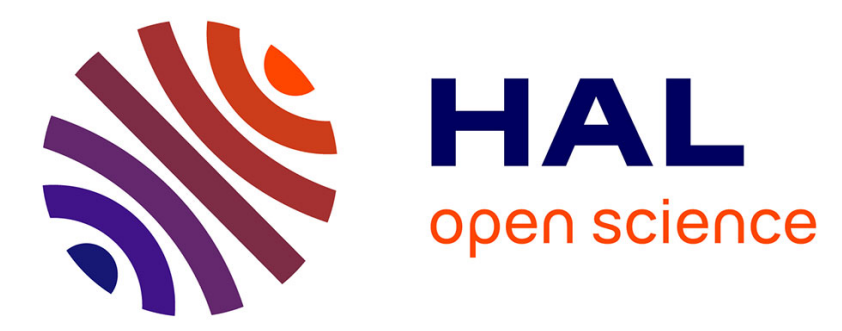

\title{
Effect of Yttrium as Alloying Element on a Model Alumina-Forming Alloy Oxidation at $1100{ }^{\circ} \mathrm{C}$
}

Christophe Issartel, Henri Buscail, Sébastien Chevalier, Jérôme Favergeon

\section{To cite this version:}

Christophe Issartel, Henri Buscail, Sébastien Chevalier, Jérôme Favergeon. Effect of Yttrium as Alloying Element on a Model Alumina-Forming Alloy Oxidation at $1100{ }^{\circ} \mathrm{C}$. Oxidation of Metals, 2017, 88 (3-4), pp.409 - 420. 10.1007/s11085-017-9750-4 . hal-01659226

\section{HAL Id: hal-01659226 \\ https://hal.uca.fr/hal-01659226}

Submitted on 8 Dec 2017

HAL is a multi-disciplinary open access archive for the deposit and dissemination of scientific research documents, whether they are published or not. The documents may come from teaching and research institutions in France or abroad, or from public or private research centers.
L'archive ouverte pluridisciplinaire HAL, est destinée au dépôt et à la diffusion de documents scientifiques de niveau recherche, publiés ou non, émanant des établissements d'enseignement et de recherche français ou étrangers, des laboratoires publics ou privés. 


\title{
Effect of Yttrium as Alloying Element on a Model Alumina-Forming Alloy Oxidation at $1100{ }^{\circ} \mathrm{C}$
}

\author{
Christophe Issartel $^{1} \cdot$ Henri Buscail $^{1}$. \\ Sébastien Chevalier ${ }^{2} \cdot$ Jérôme Favergeon $^{3}$
}

\begin{abstract}
In order to study the effect of yttrium as alloying element on the hightemperature oxidation of an alumina-forming alloy, $0.093 \mathrm{wt} \%$ ytrium was incorporated into a model $\mathrm{FeCrAl}$ alloy. Yttrium has a beneficial effect on the isothermal oxidation behavior in air at $1100^{\circ} \mathrm{C}$. Glancing angle X-ray diffraction made on a sample oxidized for $1000 \mathrm{~h}$ under thermal cycling conditions indicated that ytrium is located at the internal interface as $\mathrm{Y}_{3} \mathrm{Al}_{5} \mathrm{O}_{12}$. Secondary neutral mass spectrometry results showed that the diffusion mechanism is modified by the presence of yttrium as an alloying element. Moreover, the beneficial effect of yttrium on the alloy oxidation is also related to a reduced metallic grain size. The growth of metal grains during oxidation was especially observed on the ytrium-free $\mathrm{FeCrAl}$ alloy. It is also well established that the diffusion mechanism in the oxide scale is modified by yttrium. The aim of the present work was to show that yttrium also plays a role on the aluminum diffusion in the metallic substrate and has a strong influence on the kinetic transient stage during the $\mathrm{FeCrAl}-0.1 \mathrm{Y}$ oxidation.
\end{abstract}

Keywords Yttrium $\cdot$ Oxidation $\cdot$ FeCrAl $\cdot$ Alumina 


\section{Introduction}

The excellent oxidation resistance of $\mathrm{FeCrAl}$ alloys is due to the formation of a slow growing and adherent alumina scale. In order to increase the oxidation properties, reactive elements can be introduced in the alloy. The beneficial effect of rare earth element (REE) on the high-temperature oxidation of alloys has already been studied by several authors [1-6]. Previous works were generally conducted on industrial steels such as Kanthal AF [7,8]. Nevertheless, in such alloys other minor elements could influence the oxidation resistance at high temperature. Sulfur can also show a bad influence on scale adherence [9, 10], introduction of small amount of magnesium induces $\mathrm{MgAl}_{2} \mathrm{O}_{4}$ formation in the outer part of the alumina scale [11], and titanium and zirconium have negative effects on the alloy lifetime [12]. It is thus interesting to investigate the specific effect of yttrium on the oxidation of an alumina-forming alloy by using a high-purity model substrate. A small amount of yttrium decreases the oxidation growth rate of alumina and increases the scale adhesion on the metallic substrate. The role of yttrium in the alloys depends upon its introduction mode. The beneficial effect is observed when yttrium is introduced in the alloy and not only deposited on the surface [13, 14]. After alumina-forming alloys oxidation, Zhenyu Liu has localized the RE along alumina grain boundaries [15-17]. Nevertheless, it is very difficult to observe yttrium located inside the oxide scale. Recently, Hellström et al. [18] explained that yttrium particles become incorporated into the scale during oxidation because of metal recession. Furthermore, the beneficial effect of yttrium is related to the suppression of the linear transient stage on kinetic curves. In order to better understand the role of yttrium, the oxidation of model alumina-forming alloys at $1100^{\circ} \mathrm{C}$ has been followed by several analytical techniques such as X-ray diffraction; thermogravimetric analysis; glow discharge optical emission spectrometry.

\section{Experimental Procedures}

The two materials investigated in this study are model alumina-forming alloys. Each alloy composition is given in Table 1 . In order to study the effect of yttrium as alloying element, $0.093 \mathrm{wt} \%$ yttrium was incorporated into the model $\mathrm{FeCrAl}$ alloy to give the $\mathrm{FeCrAl}-0.1 \mathrm{Y}$ substrate. The high-purity $\mathrm{FeCrAl}$ and $\mathrm{FeCrAl}-0.1 \mathrm{Y}$ alloy elaborated by fusion of the metallic elements under vacuum. The ingot was transformed into a cylindrical bar by forging. They were provided by Pr J. Le Coze (Ecole des Mines de Saint-Etienne, France), and the analyses were made by optical emission spectroscopy (OES).

Table $1 \mathrm{FeCrAl}$ and $\mathrm{FeCrAl}-0.1 \mathrm{Y}$ alby composition in wt $\%$

\begin{tabular}{lllllllll}
\hline wt\% & Fe & Cr & Al & C & S & O & N & Y \\
\hline FeCrAl & Bal. & 19.98 & 5.00 & $<0.001$ & $<0.001$ & $<0.001$ & $<0.001$ & - \\
FeCrAl-0.1Y & Bal. & 19.70 & 5.00 & $<0.001$ & $<0.0005$ & $<0.001$ & $<0.001$ & 0.093 \\
\hline
\end{tabular}


One-mm-thick cylindrical specimens of around $2 \mathrm{~cm}^{2}$ total surface area were cut from the metallic bars. The specimens were abraded up to the 600-grit $\mathrm{SiC}$ paper, then degreased with acetone and finally dried.

In this paper, $1100^{\circ} \mathrm{C}$ is the only studied temperature. Various experiments have been realized as follows: (a) Isothermal oxidation testing was performed during $100 \mathrm{~h}$ at $1100^{\circ} \mathrm{C}$ in air under the atmospheric pressure using a Setaram TGDTA 92-1600 microthermobalance. (b) For secondary neutral mass spectrometry (SNMS) examination, samples were oxidized by $200 \mathrm{mBar}{ }^{16} \mathrm{O}_{2}$, during $2 \mathrm{~h}$ in a first time, and then $200 \mathrm{mBar}{ }^{18} \mathrm{O}_{2}$ was introduced during $4 \mathrm{~h}$ without stopping experiment. The SNMS examination of the oxide scale was carried out using a VG instrument, with an $\mathrm{Ar}^{+}$sputter energy of $10 \mathrm{keV}$ under a $45^{\circ}$ incidence angle. (c) Oxidation during $4 \mathrm{~h}$ in furnace in air was conducted. The microstructure and elemental distribution in the oxide scales were analyzed by scanning electron microscopy (SEM), energy-dispersive X-ray spectrometry (EDX) and glow discharge optical emission spectrometry (GDOES). After the 4-h oxidation, some specimens have been polished until the oxide scale has been removed and the alloy microstructure has been observed and compared to the non-oxidized alloys. (d) Cyclic oxidation $\left(20 \mathrm{~h}\right.$ at $1100{ }^{\circ} \mathrm{C}$ and $4 \mathrm{~h}$ at $20^{\circ} \mathrm{C}$ ) was made during 1000 -h oxidation time and glancing angle XRD (GAXRD) was used to analyze the scale composition from the gas-oxide interface to the oxide-metal interface. (e) In situ X-ray diffraction was followed by the acquisition of a pattern every hour during the 40 -h test at $1100{ }^{\circ} \mathrm{C}$. In situ patterns were obtained with a high-temperature Anton PAAR HTK 1200 chamber installed in a Philips X'pert MPD diffractometer (CuK $\alpha 1=0.15406 \mathrm{~nm}$ radiation).

\section{Results}

\section{Kinetic Results}

Mass gain per unit area versus time curves $(\Delta m / A=f(t))$ of alloys without Y- and yttrium-containing specimens oxidized during $100 \mathrm{~h}$ at $1100{ }^{\circ} \mathrm{C}$, in air, are reported in Fig. 1. The comparison of the kinetic curves shows that the $\mathrm{FeCrAl}$ sample has a higher weight gain during the $100-\mathrm{h}$ oxidation. The introduction of yttrium as alloying element has a beneficial effect on the oxidation rate since the weight gain is remarkably reduced all over the $100 \mathrm{~h}$ of the test. The calculation of the parabolic rate constants, from the slope of $(\Delta m / A=f(\sqrt{ } t)$ [19], evidences that the oxidation rate is close to each other (Table 2). For the specimen without $Y$, the first hours of oxidation have been neglected because a transient linear stage occurs before the parabolic behavior.

\section{SEM and Optical Micrographic Observations}

Substrates micrographs of the specimens have been made before and after 4-h oxidation in air at $1100^{\circ} \mathrm{C}$ (Fig. 2). After the 4-h oxidation, the specimens have been polished until the oxide scale has been removed. Results show a larger grains 


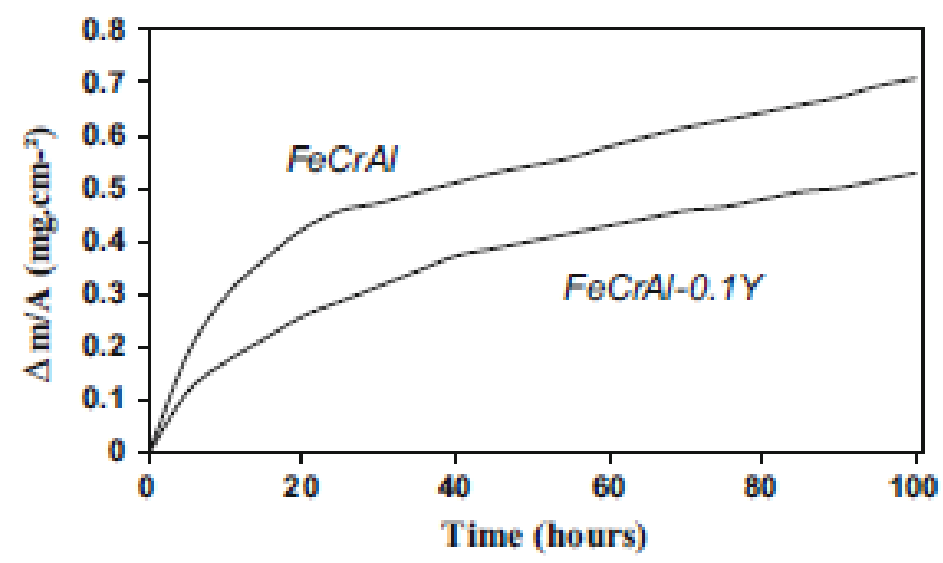

Fig. 1 Mass gain versus time curves of yttrium alloyed and alloys without $\mathrm{Y}$ at $1100^{\circ} \mathrm{C}$, in air

Table 2 Parabolic rate constants of specimens oxidized at $1100^{\circ} \mathrm{C}$ in air

\begin{tabular}{lll}
\hline Sample & FeCral & FeCrAl-0.1Y \\
\hline$k_{\mathrm{p}}\left(\mathrm{g}^{2} \mathrm{~cm}^{-4} \mathrm{~s}^{-1}\right)$ & $1.1 \times 10^{-12}$ & $9.6 \times 10^{-13}$ \\
\hline
\end{tabular}

size for the FeCrAl sample than FeCrAl-0.1Y sample before oxidation. Results also show that temperature of $1100{ }^{\circ} \mathrm{C}$ increases the grains size of $\mathrm{FeCrAl}$ sample (grains size increases by a factor of 8 ) The same temperature has not much influence on substrate grains size of $\mathrm{FeCrAl}-0.1 \mathrm{Y}$ sample (factor 1.7). On the yttriumcontaining alloy ( $\mathrm{FeCrAl}-0.1 \mathrm{Y}$ ) results show that yttrium inhibits the growth of metallic grain size. The grain sizes are listed in Table 3.

SEM observation and EDXS analysis have not permitted the detection of yttrium in the oxide scale. Nevertheless, yttrium has been detected in the substrate before oxidation and in the metallic substrate under the scale obtained after 4-h oxidation in air (Fig. 3). Before and after oxidation, the white particles are composed of pure yttrium. In both cases, they cannot be detected by XRD due to their low ratio in the alloy.

\section{SNMS Results}

On FeCrAl specimens, the SNMS results exhibit that after the two-stage experiment most of the new oxide formed with ${ }^{18} \mathrm{O}$ is located at the external interface (Fig. 4a). This means that the oxide growth mechanism implies a major cationic diffusion contribution. The ${ }^{18} \mathrm{O}$ profile also indicates that some new oxide is formed in the pre-existing $\mathrm{Al}_{2}^{16} \mathrm{O}_{3}$ scale close to the internal interface. A little contribution of oxygen inward diffusion must also be considered.

On the yttrium-containing alloy ( $\mathrm{FeCrAl}-0.1 \mathrm{Y}$ ), the SNMS profiles show that the ${ }^{18} \mathrm{O}$ peak is concentrated at the bottom of the pre-formed alumina scale, indicating then that the new oxide is formed at the internal interface (Fig. 4b). The alumina 


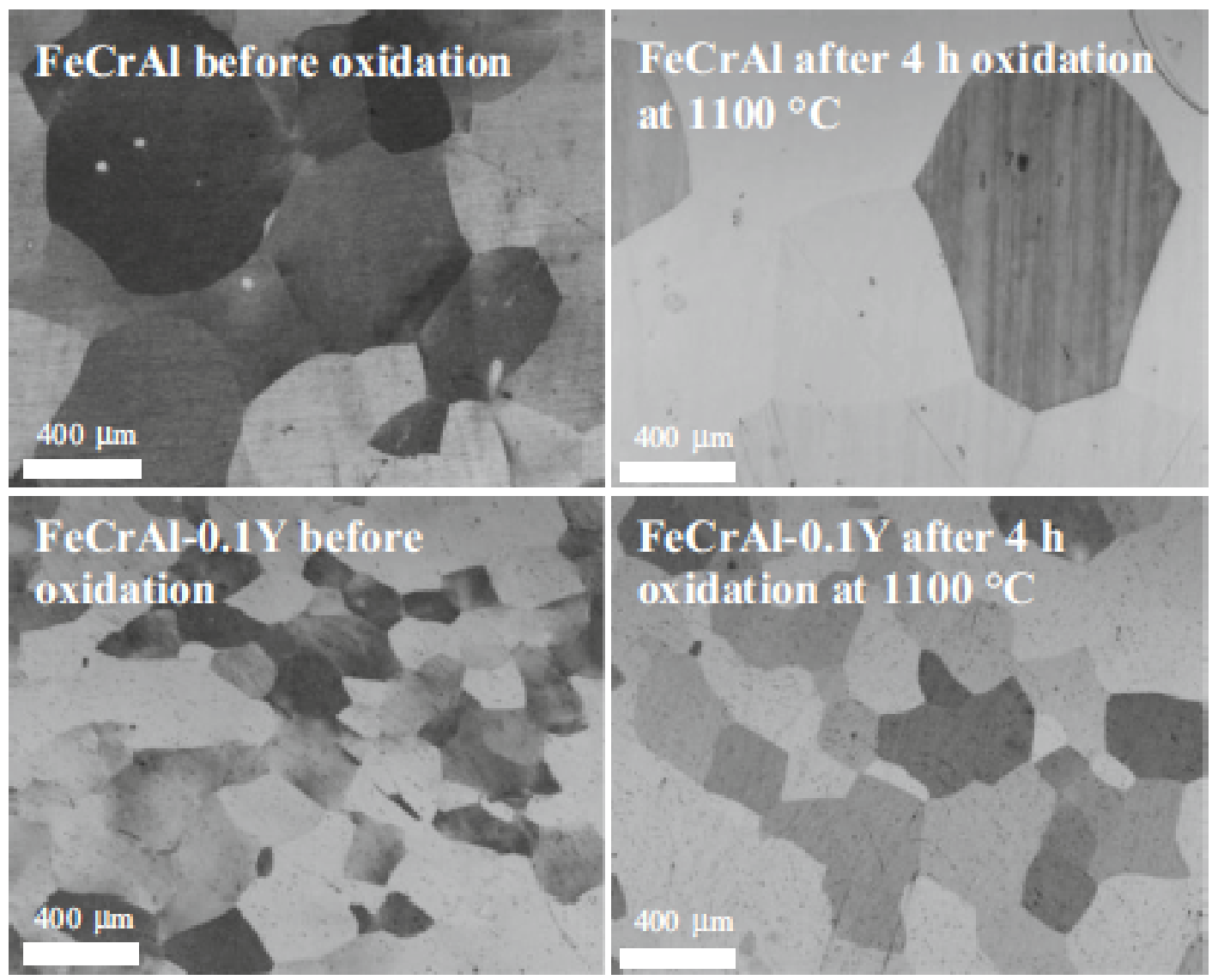

Fig. 2 Optical micrographs of yttrium alloyed and non-alloyed specimens

Table 3 Grain sizes of yttried and non-yttried specimens oxidized $4 \mathrm{~h}$ at $1100^{\circ} \mathrm{C}$ in air

\begin{tabular}{llllll}
\hline Sample & \multicolumn{2}{l}{ FeCrAl } & & \multicolumn{2}{l}{ FeCrAl-0.1Y } \\
\cline { 2 - 3 } \cline { 5 - 6 } Oxidation time & $0 \mathrm{~h}$ & & $0 \mathrm{~h}$ & $4 \mathrm{~h}$ \\
\hline Average grain size $\left(\mu \mathrm{m}^{2}\right)$ & $186 \times 10^{3}$ & $1630 \times 10^{3}$ & & $31 \times 10^{3}$ & $54 \times 10^{3}$ \\
\hline
\end{tabular}

scale is therefore growing by a predominant inward anionic diffusion process. The yttrium is mainly detected and seems to be located at the internal interface.

\section{X-Ray Diffraction}

On alloys without $\mathrm{Y}$, in situ X-ray diffraction shows the growth of a $\alpha-\mathrm{Al}_{2} \mathrm{O}_{3}$ scale (ICDD 46-1212) during the first 40 -h oxidation at $1100^{\circ} \mathrm{C}$, in air. For the FeCrAl$0.1 \mathrm{Y}$ specimens, all along the 40-h oxidation, no yttrium oxides could be detected. As observed on alloys without $\mathrm{Y}, \alpha-\mathrm{Al}_{2} \mathrm{O}_{3}$ is the only oxide growing on the substrate. Nevertheless, we have noticed some differences concerning the relative diffraction peak intensities observed. In both cases, we can well identify $\alpha-\mathrm{Al}_{2} \mathrm{O}_{3}$, 

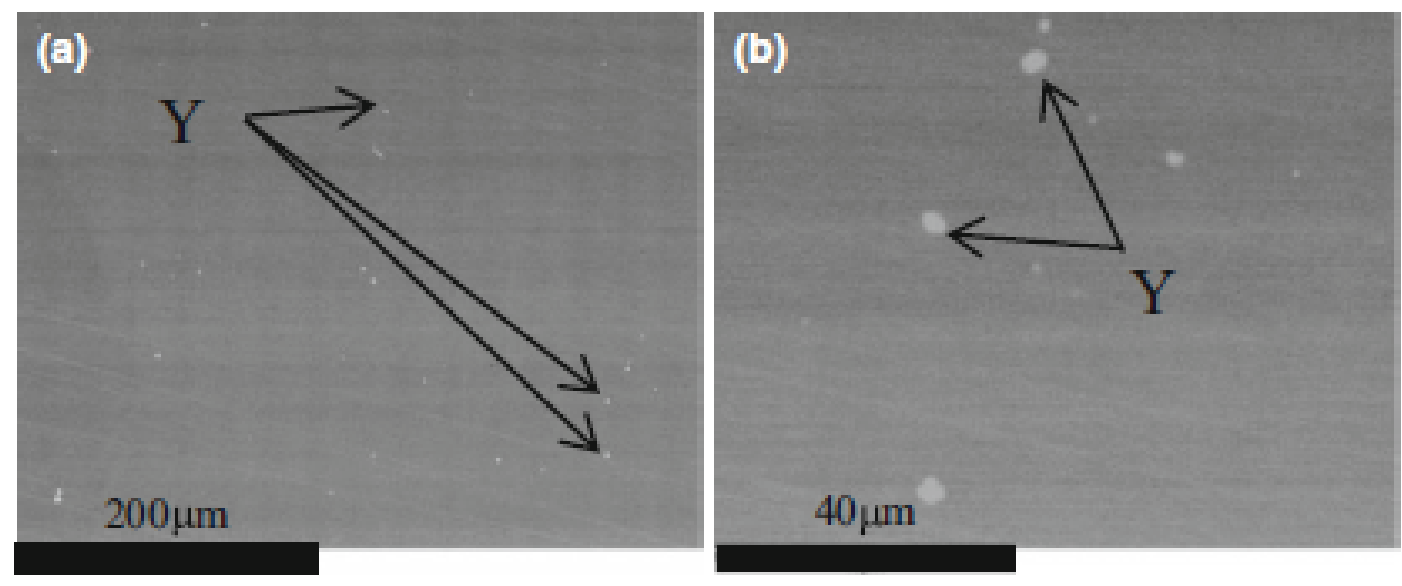

Fig. 3 SEM obtained on FeCrAl- $0.1 \mathrm{Y}$ surfaces a before oxidation and $\mathbf{b}$ after 4 -h oxidation at $1100^{\circ} \mathrm{C}$

(a)

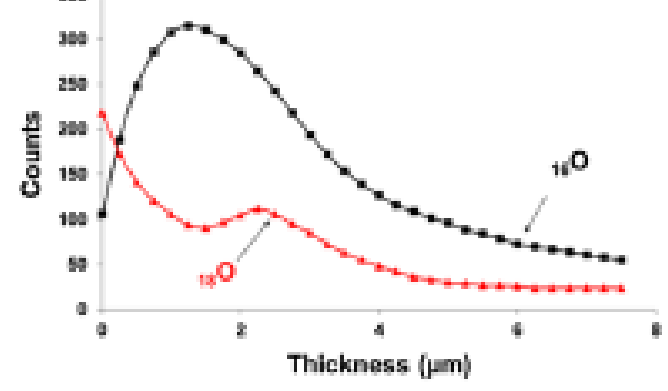

(b)

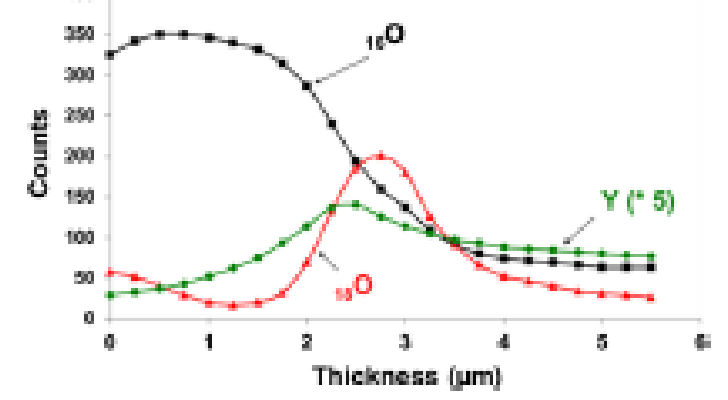

Fig. 4 SNMS results on a FeCrAl and b FeCrAl-0.1Y samples oxidized at $1100^{\circ} \mathrm{C}$ during $2 \mathrm{~h}$ in $200 \mathrm{mBar}{ }^{16} \mathrm{O}_{2}$, followed by $4 \mathrm{~h}$ in $200 \mathrm{mBar}{ }^{18} \mathrm{O}_{2}$

but it appears that this oxide grows following two different crystallographic orientations depending on the presence of yttrium.

After $1000 \mathrm{~h}$ of thermal cyclic oxidation tests, no spallation was observed on the FeCrAl-0.1Y alloy, and the analysis by glancing angle X-ray diffraction at various incident angles are performed to obtain more precise information on the scale structure (Fig. 5). On the $\theta-2 \theta$ pattern at normal incidence, the X-ray penetration depth is maximal and we can observe the $\alpha-\mathrm{Al}_{2} \mathrm{O}_{3}$ and $\mathrm{Y}_{3} \mathrm{Al}_{5} \mathrm{O}_{12}$ peaks. The pattern obtained at $2^{\circ}$ incidence shows that all the peak intensities decrease but this effect is more pronounced for the $\mathrm{Y}_{3} \mathrm{Al}_{5} \mathrm{O}_{12}$ peaks. This result would indicate that $\mathrm{Y}_{3} \mathrm{Al}_{5} \mathrm{O}_{12}$ is localized close to the scale-metal interface.

\section{GDOES Results}

Figure 6 shows the GDOES depth profiles for elemental distributions in the scales formed by oxidization for $4 \mathrm{~h}$ at $1100{ }^{\circ} \mathrm{C}$ in air. The scale/substrate interface is assumed to be located at the depth where the Fe profile increases, near $3 \mu \mathrm{m}$. The profiles indicate that the scales formed on the yttried and non-yttried samples were composed of an alumina layer. Nevertheless, it can be observed a more important chromium presence on the top of the alumina layer for $\mathrm{FeCrAl}-0.1 \mathrm{Y}$. The profiles 


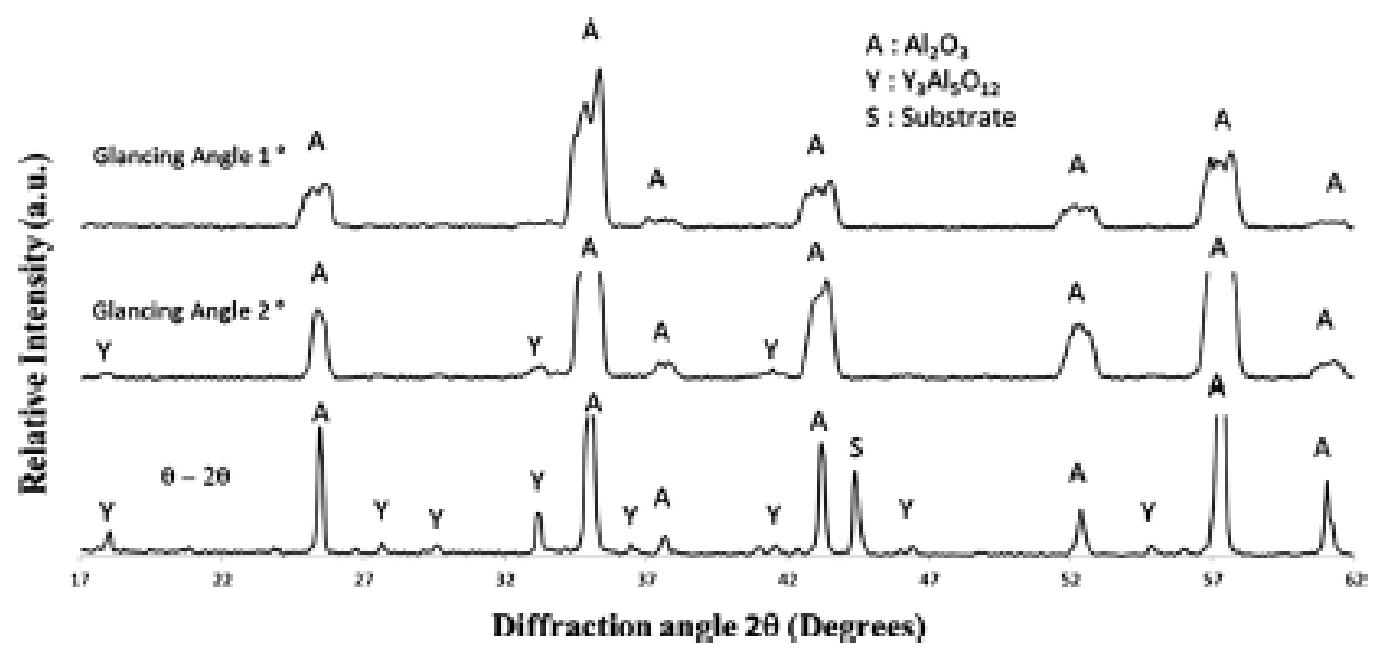

Fig. 5 Main glancing angle $\mathrm{X}$-ray pattems obtained on yttrium alloying $\mathrm{FeCr} A \mathrm{l}$, oxidized at $1100^{\circ} \mathrm{C}$, in air, during $1000 \mathrm{~h}$ of cyclic oxidation

(a)

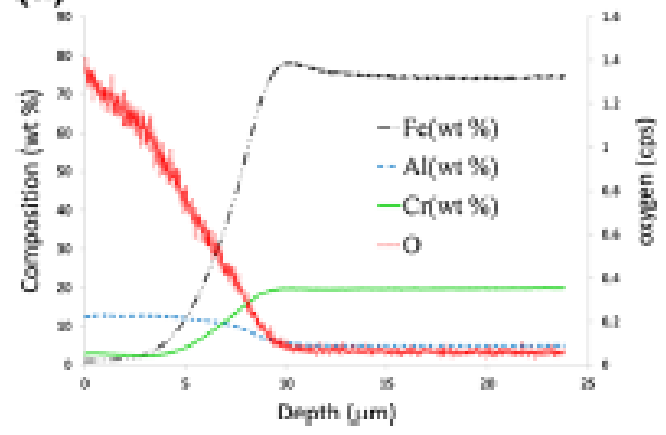

(b)

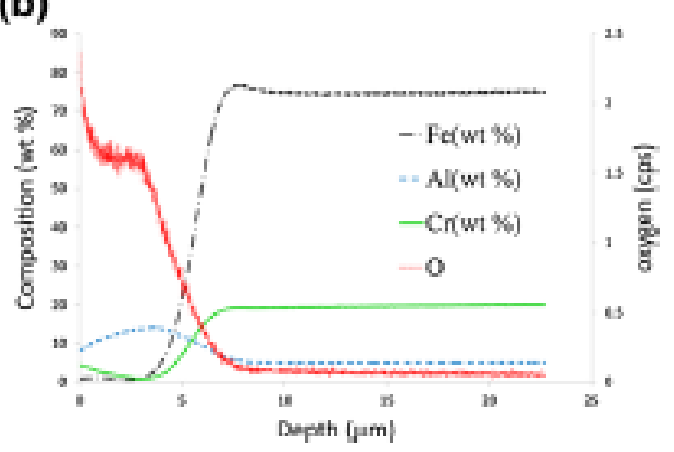

Fig. 6 GDOES depth profiles for the scales formed by oxidation for $4 \mathrm{~h}$ at $1100^{\circ} \mathrm{C}$ in air: a FeCrAl, b FeCrAl-0.1Y

also indicate that diffusion of aluminum is not the same in the two samples. The flat profile of aluminum on the $\mathrm{FeCrAl}$ proves that diffusion rate is fast enough in the substrate to supply the scale with aluminum. For the FeCrAl-0.1Y sample, the aluminum and oxygen profiles indicate that diffusion of $\mathrm{Al}$ is less important than diffusion of oxygen. The decrease in aluminum diffusion rate is shown in the scale, but it is also true in the metallic substrate.

\section{Discussion}

On FeCrAl specimens oxidized at $1100{ }^{\circ} \mathrm{C}$, in situ XRD shows that only $\alpha-\mathrm{Al}_{2} \mathrm{O}_{3}$ is formed all along the oxidation process. $\alpha-\mathrm{Al}_{2} \mathrm{O}_{3}$ is the only oxide observed during the transient oxidation stage. This result can be related to other works which have shown that $\alpha-\mathrm{Al}_{2} \mathrm{O}_{3}$ is the only oxide detected on oxidized FeCrAl specimens after cooling to room temperature $[15,20,21]$. On the FeCrAl-0.1Y alloy, yttrium oxides are not detected by in situ X-ray diffraction after 40-h oxidation. 
The SNMS examination of the oxide scale shows that a mixed diffusion process occurs on the model alumina-forming alloy oxidized at $1100^{\circ} \mathrm{C}$ (Fig. 4a), whereas a predominant inward oxygen diffusion process is observed in the case of yttriumcontaining specimens (Fig. 4b). The mixed diffusion process promotes ridges formation and a less protective and adherent scale as proposed by Pint et al. [8]. The change in the diffusion mechanism is a consequence of the yttrium presence, and an improvement of the corrosion resistance for the $\mathrm{FeCrAl}-0.1 \mathrm{Y}$ alloy is observed.

In Fig. 6, glancing angle XRD results show that $\mathrm{Y}_{3} \mathrm{Al}_{5} \mathrm{O}_{12}$ is present close to the internal interface. But the presence of $\mathrm{Y}_{3} \mathrm{Al}_{5} \mathrm{O}_{12}$ at this interface cannot explain the change in diffusion mechanism because $\mathrm{Y}_{3} \mathrm{Al}_{5} \mathrm{O}_{12}$ is only observed after long-term oxidation, as it is the case during 1000 -h thermal cycling tests. $\mathrm{Y}_{3} \mathrm{Al}_{5} \mathrm{O}_{12}$ could not be detected by in situ XRD after 40-h oxidation. It seems to be mainly located at the internal interface. $\mathrm{Y}_{3} \mathrm{Al}_{5} \mathrm{O}_{12}$ belongs to the garnet $\mathrm{YAG}$ oxide type structure, and this oxide has been described by other authors [22-24]. As proposed by Liu or Wood [15, 20], yttrium is probably located at the oxide grain boundaries. It is also mentioned that $\mathrm{Y}_{3} \mathrm{Al}_{5} \mathrm{O}_{12}$ is often found segregated along the $\alpha-\mathrm{Al}_{2} \mathrm{O}_{3}$ grain boundaries [25-27].

Yttrium is not easily observed in the alumina scale, but it is detected in the metallic substrate. Figure 3 clearly exhibits that yttrium is still present under the scale after 4-h oxidation. In light of the anionic diffusion mechanism, Hellström et al. [18] explained that the yttrium particles can be incorporated into the scale during oxidation because of metal recession.

Isothermal kinetic results (Fig. 1) have shown that alloys without $\mathrm{Y}$ have a higher weight gain compared to $\mathrm{FeCrAl}-0.1 \mathrm{Y}$ samples after 100 -h oxidation at $1100^{\circ} \mathrm{C}$ in air. But it cannot be explained by the presence of yttrium in the scale because we have shown that it takes time for yttrium to be introduced inside the oxide scale. The FeCrAl-0.1Y sample follows a parabolic growth rate from the beginning of the oxidation test, contrarily to the FeCrAl sample which presents a transient linear stage. It then appears that yttrium plays a role but it cannot act inside the alumina scale at the early stage of oxidation.

Huntz [28] proposed that the oxide scale growth is controlled by "the slowest process of dominant route", i.e., the slowest step of the fastest route. This author considers two routes: route 1 which considers the cation process and route 2 which considers the anion process. The possible limiting steps applied to this study are listed Table 4:

Generally, the fast reactions of adsorption are not considered to be the limiting steps. Thus, if the oxide scale growth is controlled by one (or several) diffusional phenomena (route 1 or 2), the oxidation rate behavior is parabolic. And if the oxide scale growth is controlled by a chemical reaction, a linear rate behavior is observed.

Concerning the $\mathrm{FeCrAl}-0.1 \mathrm{Y}$ sample kinetic curve, a parabolic rate behavior is followed from the beginning of the test. No transient stage is observed. It indicates that a diffusional process controls the oxide scale growth. Before the formation of a continuous $\mathrm{Al}_{2} \mathrm{O}_{3}$ scale, $\mathrm{Al}$ or $\mathrm{O}$ diffusion in alumina cannot be the limiting step of the oxide scale growth. If the limiting step of the cationic and anionic routes cannot be the aluminum or oxygen diffusion in alumina, then it should be the Al diffusion in the alloy. It corresponds to the first step of route 1 (Table 4 ) and this process 
Table 4 Limiting step of oxide scale growth

\begin{tabular}{ll}
\hline Route 1 & Route 2 \\
\hline $\mathrm{Al}$ diffusion in $\mathrm{FeCrAl}$ & $\mathrm{O}_{2} \rightarrow 2 \mathrm{O}_{\text {six }}$ \\
$\mathrm{Al} \rightarrow \mathrm{Al}^{3+}+3 e^{-}$ & $\mathrm{O}_{\text {ab }}+2 e^{-} \rightarrow \mathrm{O}^{2-}$ \\
$\mathrm{Al}$ diffusion in $\mathrm{Al}_{2} \mathrm{O}_{3}$ & $\mathrm{O}$ diffusion in $\mathrm{Al}_{2} \mathrm{O}_{3}$ \\
$2 \mathrm{Al}^{3+}+3 \mathrm{O}_{\text {ak }} \rightarrow \mathrm{Al}_{2} \mathrm{O}_{3}$ & $3 \mathrm{O}^{2-}+2 \mathrm{Al} \rightarrow \mathrm{Al}_{2} \mathrm{O}_{3}$ \\
\hline
\end{tabular}

controls the initial oxide scale growth before the establishment of a continuous alumina scale. This is a diffusional step and this corresponds to the parabolic rate law followed from the beginning of the test (Fig. 1). According to the yttrium-free FeCrAl oxidation kinetic curve (Fig. 1), a transient linear stage is observed. In this case, the Al diffusion in the substrate is fast enough and cannot be the limiting step of route 1 . The chemical reaction between aluminum and oxygen controls the oxide scale growth during the transient stage, before the formation of a continuous $\mathrm{Al}_{2} \mathrm{O}_{3}$ scale.

After the transient stage, a continuous alumina scale is formed on both alloys. A diffusional process leads to a parabolic behavior. The $k_{\mathrm{p}}$ values measured on the FeCrAl and FeCrAl-0.1Y are close to each other (Table 2). It indicates that similar limiting diffusion processes are involved through the alumina scales. Figure $4 \mathrm{~b}$ emphasizes the fact that the alumina scale grows by an inward anionic diffusion process on the FeCrAl-0.1Y alloy. The aluminum diffusion in alumina is slightly faster than oxygen diffusion in alumina. At $1100^{\circ} \mathrm{C}$, Le Gall has found that $D_{\mathrm{N}} /$ $D_{\mathrm{O}}=24$, with $D_{\mathrm{Al}}$ and $D_{\mathrm{O}}$, respectively, the diffusion coefficients of aluminum and oxygen in an alumina scale [29]. The anionic oxygen diffusion in alumina scale is therefore considered as the limiting step.

On the FeCrAl-0.1Y alloy, the presence of chromium (Fig. 6b) in the outer part of the scale can be explained by the process involved during the transient stage. With the measurement of Al diffusion in an yttried metallic substrate, Lesage exhibited that there is a competition between the oxidation rate governed by the oxygen diffusion through the oxide scale to the oxide/metal interface and the diffusion of aluminum in the substrate to the metal/oxide interface [30]. In the present work, the low aluminum diffusion rate in the yttried substrate allows the chromium oxidation during the transient stage (Fig. 6b). After the transient stage, as long as the process is governed by anionic diffusion, the chromium stays close to the outer part of the scale. This is in accordance with what is proposed by other authors who indicate that the $\mathrm{Al}_{2} \mathrm{O}_{3}$ scale structure corresponds to an outward growing of $\mathrm{Al}_{2} \mathrm{O}_{3}$; a continuous $\mathrm{Cr}$-rich zone; and an inner layer of pure $\alpha-\mathrm{Al}_{2} \mathrm{O}_{3}$ [7-31]. The interface between the two alumina subscales corresponds to the original metal surface, and chromium is incorporated in this zone during the transient oxidation stage [18]. The textures of both alumina scales have been discussed by several authors. The duplex structure of alumina is made of equiaxed grains in the external part and columnar alumina grains in the inner one [32]. The anionic and cationic diffusions contribute to the scale development (Fig. 4a), and an equiaxed grain morphology of the scale is observed [33]. 
Our results show that yttrium acts on the $\mathrm{Al}$ diffusion in the metallic substrate. Lesage [30] has shown that at relatively low temperatures $\left(1000-1080^{\circ} \mathrm{C}\right)$, oxygen diffuses faster in alumina than aluminum in an yttried substrate. And above $1080^{\circ} \mathrm{C}$, the diffusion rate of $\mathrm{Al}$ increases faster than oxygen in the scale. In Lesages's work, the $1080{ }^{\circ} \mathrm{C}$ temperature corresponds to the intermediate temperature between the aluminum atoms flow and the oxygen flow at the metal/oxide interface. But the alloy microstructure consists of large centimetric elongated grains. It means that the contribution of grain boundary diffusion is negligible. Our results show that the FeCrAl-0.1Y alloy microstructure of is not the same compared to the FeCrAl one (Fig. 2). Yttrium appears to block the alloy grain growth during oxidation and decreases the aluminum diffusion in the metallic substrate. Metal grains remain smaller, and thus, the number of grain boundaries remains relatively high.

The apparent diffusion coefficient can be calculated following Eq. (1):

$$
D_{\text {app }}=(1-f) D_{\mathrm{sh}}+f D_{\mathrm{gh}}
$$

$D_{\mathrm{sb}}$ and $D_{\mathrm{gh}}$ are, respectively, the substrate and grain boundary diffusion coefficients and $f$ is the volume fraction of grain boundaries: $f=3 \delta / \varphi$ where $\delta$ is the grain boundary width and $\Phi$ is the diameter of the grains.

If the grain size is small, $f$ increases and $D_{\mathrm{gh}}$ is more influent in the expression of $D_{\text {app. }}$. In this study, yttrium favors grain boundary aluminum diffusion in the alloy. Results show that yttrium also decreases $D_{\text {app. }} D_{\text {gb }}$ is certainly lower in the Y-containing FeCrAl than in the $\mathrm{FeCrAl}$ without yttrium. It is probably also right for $D_{\text {sh. }}$. If $D_{\text {app }}$ of aluminum in Fe [34], FeCrAl [35] and FeCrAlY [30] have been measured, the contribution of grain boundaries was never discussed.

Yttrium is well known to improve the alumina scale adherence. The influence of the alloy grain size can also be considered. Horibe and Nakayama [36] have already stated that on a $\mathrm{Fe}-18 \mathrm{Cr}$ alloy the grain growth of the ferrite might promote the disruption of the initial oxide. Sasa and Nakayama [37] confirms that grain growth contribute to the breakaway and subsequent abnormal oxidation for a $\mathrm{Fe}-17 \mathrm{Cr}$ at $1000{ }^{\circ} \mathrm{C}$. Several authors have observed the influence of average grain size of the metal on oxidation and scale adherence [38-42]. In the present work (Fig. 2) shows that the alloy grain growth is especially observed on the $\mathrm{FeCrAl}$ and the scale adherence is much better on FeCrAl-0.1Y.

\section{Conclusions}

The present work shows that on the yttrium-containing alloy ( $\mathrm{FeCrAl}-0.1 \mathrm{Y}$ ) the alumina scale is growing by a predominant inward anionic diffusion process which leads the formation of a more protective and adherent scale. The role of yttrium is to block the alloy grain growth during oxidation and decreases the aluminum diffusion in the alloy. The duplex structure of the alumina scale corresponds to an external thin equiaxed subscale and an inner columnar one. The interface between the two layers of alumina has been reported to correspond to the original metal surface, and 
chromium is incorporated in this zone during the transient oxidation stage. Yttrium is well known to improve the adherence of alumina scales. This work shows that the oxidation mechanism is also related to the influence of yttrium on the alloy grain size.

Acknowledgements The authors thank Prof. I. Le Coze for providing the model base FeCrAl and FeCral0.1Y alloys. They are also grateful to Prof. G. Borchardt and Dr. Strehl for the ${ }^{16} \mathrm{O}_{2}$ and ${ }^{18} \mathrm{O}_{2}$ oxidations, and Prof.S. Weber for the SNMS experiments.

\section{References}

1. K. Messaoudi, A. M. Huntz and B. Lesage, Materials Science and Engineering A 247, 248 (1998).

2. J. Jedlindki, Oxidarion of Mevals 39(1/2), 55 (1993).

3. S. Chevalier, G. Strehl, H. Buscail, G. Borchardt and J. P. Larpin, Materials and Corrosion 55, 352 (2004).

4. X. G. Zheng and D. J. Young, Corrosion Science 40(4/5), 741 (1998).

5. K. Przybylski and G. J. Yurek, Makerials Science Forum 431 (1989).

6. P. Castello, F. H. Stott and F. Gesmundo, Corrosion Sckence 41, 901 (1999).

7. R. Queff, H. Buscail, E. Caudron, C. Issartel and F. Riffard, Corrosion Science 45, 1815 (2003).

8. B. A. Pint, A. J. Garatt-Reed and L. W. Hobbs, Materials at High Temperanures 13, 3 (1995).

9. T. Amano, T. Watanabe and M. Michiyama, Oxilation of Mevals 53, 451 (2000).

10. R. Bousquet, D. Fayeulle, E. Bruyere and F. Bertrand, Oxilation of Mevals 80, 13 (2013).

11. P. Untoro, M. Dani, H. J. Klaar, J. Mayer, D. Naumenko, J. C. Kuo, and W. J. Quadakkers, Marerials Aspects in Automothe Catalyric Converters, 271 (2002).

12. D. Naumenko, J. Le-Cone, E. Wessel, W. Fischer and W. J. Quadakkers, Materials Transactions 43, $168(2002)$.

13. S. Chevalier, A. P. Dawah Tankeu, H. Buscail, C. Issartel, G. Borchardt and J. P. Larpin, Materials and Corrosion 55, 610 (2004).

14. S. Chevalier, G. Strehl, H. Buscail, C. Issartel, G. Borchard and J. P. Larpin, Maserials and Cor. rosion $57,476(2006)$.

15. Z. Liu, W. Gao and Y. He, Oxidanion of Metals 53(3/4), 341 (2000).

16. K. Przybylski, A. J. Garratt-Reed and G. J. Yurek, Journd of the Electrochemical Sociery 135, 509 (1988).

17. K. Bongartz, W. J. Quadakkers, J. P. Pfeifer and J. S. Becker, Surface Science 292, 196 (1993).

18. K. Hellström, N. Israelsson, N. Mortazavi, S. Canovic, M. Halvarsson, J. E. Svensson and L. G. Johansson, Oxidation of Merals 83,533 (2015).

19. B. Pieraggi, Oxidarion of Metals 27, 177 (1987).

20. G. C. Wood and F. H. Stott, in High Temperature Corrosion, Nace-6, eds. R. A. Rapp (NACE Intemational, 1958), p. 227.

21. R. Prescott and M. J. Graham, Oxidation of Merals 38(1/2), 73 (1991).

22. K. M. N. Prasanna, A. S. Khanna, R. Chandra and W. J. Quadakkers, Oxidation of Metals 46(5/6), 465 (1996).

23. E. Schumann, Oxidarion of Merals 43(1/2), 157 (1995).

24. R. Queff, H. Buscail, E. Caudron, and F. Riffard, La revue de Mésallurgie-SF $2 M 147$ (2000).

25. M. K. Loudjani, C. Haut and S. Parisot, Radiation Effects and Defects in Sollds 134, 233 (1995).

26. M. K. Loudjani and C. Haut, Journal of the European Ceranic Sociery 16, 1099 (1996).

27. B. A. Pint, Oxidasion of Merals 45(1/2), 1 (1996).

28. A. M. Huntz, Journal de Physique III 5, 1729 (1995).

29. M. Le Gall, A. M. Huntz, B. Lesage, C. Monty and J. Bernardini, Joumal of Materials Science 30, 201 (1995).

30. B. Lesage, L. Maréchal, A. M. Huntz and R. Molins, Defect and Diffusion Fonam 194-199, 1707 (2001)

31. F. Liц, M. Halvarsson, K. Hellström, J. E. Svensson and L. G. Johansson, Oxidarion of Merals $\mathbf{8 3}$, 441 (2015) 
32. S. Chevalier, J. P. Larpin, P. Dufour, G. Strehl, G. Borchardt, K. Przybylkki, S. Weber and H. Scherrer, Materials at High Temperanures 20(3), 365, (2003).

33. J. R. Blachère, E. Schumann, G. H. Meier and F. S. Pettit, Scrị̀ta Materialia 49, 909 (2003).

34. I. A. Akimova, V. M. Mironov and A. V. Pokoyev, Fiz Meral. Meralloved 56(6), 1225 (1983).

35. A. Heesemann, E. Schmidtke, F. Faupel, A. Kolb-Telieps and J. Klower, Scripta Materialka 40(5), 517 (1999).

36. S. Horibe and T. Nakayama, Comosion Science 15, 589 (1975).

37. K. Sasa and T. Nakayama, Corrosion Science 17, 783 (1977).

38. M. D. Merz, Metallurgical Transactions 10A, 71 (1979).

39. S. N. Basu and G. J. Yurek, Oxilarion of Mevals 36(3/4), 281 (1991).

40. I. Murris, Y. P. Jacob, V. A. C. Haanappel and M. F. Stroosnijder, Oxidarion of Merals 55(3/4), 307 (2001).

41. X. Peng, J. Yan, Y. Zhou and F. Wang, Acta Maserialia 53, 5079 (2005).

42. J. H. Kim, D. I. Kim, S. Suwas, E. Fleury and K. W. Yi, Oxidation of Merals 79, 239 (2013). 